\title{
"Everybody has their own Dream": Nail houses and Resistance to the Landscape of Globalization in Contemporary China
}

\begin{abstract}
The transformation of the Chinese landscape is embodied by the figure of new, hyper-modern cityscapes. With the influx of hundreds of millions of people from rural to urban areas, China's economic reform process is dominated by the production of space designed to instill a new ideal of modern economic subjects for Chinese identity. However, China's modernization is complicated by the emergence of a recent urban phenomena: dingzibu, or nail-houses. Nail- houses are points of resistance where individuals refuse to abandon their homes when traditional urban districts are demolished for urban renewal. By examining personal testimonies of nail-house inhabitants and visual representations of traditional urban communities in contemporary Chinese cinema, it will be argued that nail-house protests' resistance to the disappearance of traditional urban-community culture is a symptom of the logic of globalization. To this end, Frederic Jameson shall be invoked to argue that globalization forces the creation of local national worlds that are antagonistic to all others, including those within their own space. Drawing on Hannah Arendt, insofar as the collapse of the public and private sphere for the sake of economic interest in China can be understood as reducing the difference of personal identity to create national homogeneity, nail-house protests reveal a common condition of exile endemic to the process of global modernity as a whole.

KEYWORDS: Globalization; Global Modernity; Capitalism; China; Nail-House Protests; Identity
\end{abstract}




\section{The Case of China: Exception, Alternative, or Rule of Global Modernity?}

With the influx of hundreds of millions of people from rural to urban areas, the transformation of the Chinese landscape has come to be embodied by the figure of new, hyper-modern cityscapes. While this process of (re)development and (re)construction of urban infrastructure has been met with awe by some western observers, ${ }^{1}$ its relationship to the larger narrative of globalization is as contested as the ways to describe China's particular form of capitalism. In this regard, China's recent past is simultaneously appropriated as a case of 'alternative' modernity defined by a new potential for political reassertion in the conditions of depoliticized postmodernity and as an exception to the rule of global modernity itself where political interference in the "natural order" of market mechanisms is seen to constantly threaten China's future. ${ }^{2}$

The case of China is further complicated, however, by the fact that its reform process has been dominated by the production of space. This statement may appear odd considering the ubiquity of goods bearing the mark "Made in China." But as Jing Nie confirms in her article "A City of Disappearance," from Deng Xiaoping's initial policies of "Reform and Openness" in the 1980's until today, "the production of space, which fosters marketization and urbanization, is not initiated by a certain mode of production as one expects to find in capitalist countries" (Nie 2009: 197). Rather, space has had to be manipulated and re-configured to accommodate the demands of the new capitalist economy. Perhaps our very dependence on, and unease with, cheap products arriving in the global market from the pastfrom a place whose unwillingness to relinquish its allegiance to socialism elides the discursive potential of globalization narratives- has not only blinded Western academics and media outlets to the fact that the production of space significantly more valuable than the production of goods in China, but that it is in this drastic spatial reconfiguration of the country that struggles concerning identity take place (Zhang 2011: 726).

It is within this context that a new urban phenomena has emerged in China: ding$z i h u$, or nail houses. The term dingzibu is a neologism that denotes a nail which is unable to be hammered down into a piece of wood. As such, nail houses are points of resistance where individuals refuse to abandon their homes as a traditional urban district is being demolished for urban renewal. These protests often culminate in harrowing scenes: a single home will remain in the middle of a construction site deprived of the basic necessities for life such as electricity or running water; or a house could remain totally isolated, surrounded by a new highway; or the house may be demolished without notice, perhaps when the inhabitants have left for work or, worse yet, with them still inside. These descriptions may appear to present a condition of radical uniqueness, again, pertaining to some past, a propensity for violence within capitalist development that no longer resonates in already developed countries. However, I will claim that as the people inhabiting these spaces maintain 
a common status of non-belonging, a consideration of how nail houses figure into China's reform process allows us to open up a crucial vantage point, one that reveals a shared condition of exile endemic to the coordinates of global modernity.

Our present concern, then, is not to offer a comprehensive survey of the multiple forms of resistance staged in the phenomena of nail houses. Rather, we simply wish to open up a discussion about the nature of these new spaces and the people that inhabit them so as to re-examine what it means and costs to be modern, to exist "just now." To this end, we shall proceed along two main lines of thought: the first shall be an analysis of nail-houses within urban space itself, so as to understand their relation to traditional forms of public and private spheres; the second will look at the psychic space of the nail-house inhabitants. By moving between these new spaces of dwelling and our traditional conceptions of them, we shall reveal common conditions of exile which rather than simply deviating from or disrupting our past, in the sense of an alternative or exception to modernity, demonstrates how the process globalization continuously poses a threat to all notions of identity and belonging. My wager is that by implicating the historical vision of the West and the process of globalization in the destiny of China we may, to borrow from Hannah Arendt, begin again to think about what we are doing in the age of global modernity.

\section{Brief Remarks on Chinese Resistance to the Landscape of Globalization}

Almost a decade into China's economic reforms, the drastic reconstruction of the country's urban landscapes and the reorientation of daily life towards integration into global markets began to create a rift in the country's social identity. Commenting on the effects of this transitionary period, in 1988 the dissident journalist Liu Binyan writes "the biggest problem we face today in China is not commodity prices or the cost of living. [...] The most serious problem is the wide spread spiritual malaise among people of all walks of life, a growing mood of depression, even despair, [and] a loss of hope for the future" (Lin 1990:22). Attempting to ease the growing tensions amongst Chinese citizenry, a period of lax intellectual, cultural and social censorship was allowed by the Chinese government in the late 1980s. It is in this climate that in June and August of 1988, a six-part documentary entitled Heshang, or River Elegy aired on China Central Television. Speaking to the survival of China's traditional culture, the fifth part of the film, "A New Age," opens with an another warning about the cost of modernization in China: "How many Chinese people are there nowadays who clearly realize that reform doesn't just mean [...] color TVs, refrigerators and higher salaries. [...] In the majority of cases, and in its deeper sense, reform is rather a burst of pain in which a civilization is transformed, a task fraught with danger [...] which will require sacrifices from our generation and even several yet to come" (Su and Wang 1994: 228 Emphasis added). What is described by these two instances from the late 1980s is an overwhelming unbebagen 
in der Kulture, or malaise in culture. But in China's new landscape, this malaise seems to have largely disappeared as traditional Chinese culture has seeded to the leitkulture of commodity consumption and metropolitan arrangements.

As a result of the privileging the production of space, Wade Shepard, in his book Ghost Cities of China, describes urban transformation in China as a process where "the old is being replaced with the new, and the new is being replaced with the newer, in a cyclical process of creation and destruction" (Shepard, 2015: 39). For a nation that boasts a continuous narrative that can be traced back almost 4000 years, contemporary China has effectively been emptied of all signs of its history. In this regard, the effects of the economic reforms upon the people of China has shifted from anxiety about the future to a mourning of the past. It is in this way that the nail-house protests arise as a desperate attempt of individuals to hold onto their personal history and communities as traditional urban spaces are demolished to make way for rational, economic districts. As we shall see, inherent to the process of urban renewal is the collapse of the traditional public and private sphere for the sake of economic interest in China, with the effect of levelling down the identity of personal difference to create national homogeneity. As such, it is only fitting that we allow the voices of nail-house inhabitants to speak to their lived experiences. By recounting two stories of nail-houses protests we shall connect the dislocation of individuals from their home-and the loss of their identity that ensues-to Hannah Arendt's critique in her essay “The Rights of Man'What are they?" of the modern public sphere as a space where "men cannot act or change at all" (Arendt 1949: 33). ${ }^{3}$ The point here is neither to moralize these acts of resistance as noble efforts against the universal corrupting force of globalization, nor is it to glorify these individuals attachment to the past in some nostalgic way. Rather, the new exilic state of nail-house protests allows us to shed light on the real consequences of forcefully implementing what Frederic Jameson identified as the defining feature of globalization's impact on identity: "the becoming cultural of the economic, and the becoming economic of the culture" (Jameson, 1998: 60).

\section{Nail Houses and China's Traditional Urban Communities:}

If the 2008 Beijing Olympics was a display of China's successful entry into the world economy, then the 2010 World Expo in Shanghai demonstrated that the country had once again become a global power. The city used the event to justify a decade long process of reconstruction and development of the business district along the Huangpu River. During the late $19^{\text {th }}$ and early $20^{\text {th }}$ century this area was named the "Bund," or alliance in German, by Western banks and countries who used it to establish a soft colonial presence in China. Therefore, what better place to reveal the image of "the next great world city" at an international event whose theme was "Better City, Better Life" (Shepard: 11)? 
However, for the inhabitants along the Huangpu River, forced evictions became a routine part of life as entire urban communities were reclaimed to support the "public interest" of Shanghai, a popular slogan used in proxy for the reform policies of the Chinese government. Though technically Chinese law stipulates that "all persons should possess a degree of security of tenure which guarantees legal protection against forced eviction, harassment and other threats," since the founding of the People's Republic of China the CCP has owned all the land (27). So while an individual may own their home, a common case in traditional urban communities where houses are inter-generational spaces, the land a house sits on can be requisitioned at any point for minimal compensation. And yet despite the legality of the relocation process in Shanghai, when the time came for inhabitants to leave their homes and lives behind some refused.

This was the case of Mr. Han and his family who vocally cried out against the actions of Shanghai while attempting to go on with their lives in what remained of their community. Mr. Han told his family's story to a reporter from the Daily Telegraph: "My house was on the main site of the expo. They waited until we left home one day and then knocked it down. I have not had any payment for my property and, because I complained, my son was refused entrance to university and the army. I am unemployed, and so is my wife and son. We live on the bare minimum" (10). In this case, we can understand the effects of opposing the redevelopment of Shanghai as a double displacement. Mr. Han's family lost not only their past lives as it was embodied by their home and community, but moreover the possibility of integrating themselves into the fabric of the new Shanghai. So unlike the migrant worker who experiences a loss of self by labouring in a space they cannot be accepted into, one of the risks of nail-house protests is being forced to inhabit a place that was once yours but in a new public sphere that refuses to accept you. With such stark consequences, the question arises as to why individuals would risk staging a nail-house protest? Our second testimony speaks to logic of resistance in China's globalized landscape.

In the fall of 2013, the city of Taizhou was in the middle of being rebuilt. An urban space whose history spans back to the Han dynasty that originated in the 3rd century BCE, the totalizing project of redevelopment in Taizhou witnessed "the ancient neighbourhood of meandering alleyways and age-old old brick homes that covered this area ... cleared away, effectively erased from the slate of modern China" (28). At this time only a single house remained, occupied by eight members and four generations of the Zhang family whose ancestors had first come to Taizhou 300 years earlier (29). Wade Shepard interviewed Mrs. Zhang about her family's experience, their history and what they would say to Wang Jianlin, the richest man in China and the CEO of the company charged with the reconstruction of Taizhou, about their situation: 
'We have not left the house in three months', Mrs. Zhang told me 'because if we do they will destroy it. We have someone bring food in to us.' ... 'In China', Mrs. Zhang continued, 'when people don't have a house they have nothing. ...I asked Mrs. Zhang what she would say to Wang Jianlin if she had the opportunity: 'I would tell him that everybody has their own dream, not everyone wants to live in an apartment....This represents our roots', she said. 'Chinese culture cannot be replace by money. What a pity to destroy this.' A week or so later the eviction squad showed up. 'It was around three in the morning. They closed off the street and a hundred police in riot gear charged in', a man who witnessed the event told me.... The Zhang family went down with their ship. (28-31)

Between Wade Shepard's description of Taizhou and Mrs. Zhang's statements we are able to glimpse into the complex matrix that constituted traditional Chinese identity in urban communities. It would be a superficial procedure to try and parse apart the personal and private narrative of a family's roots in their old-brick homes from the hutong, those public alleyways where identities are formed by residents who "smell and taste each others' meals and exchange help and favors"(Nie: 203). In precisely this way, when Mrs. Zhang equates the absence of a home to having nothing, she evokes the symbiotic nature of belonging in traditional urban communities where the private realm extends out into public space, so individuals simultaneously shape and are shaped by common rituals, practices and values.

Zhang Yang's 1999 film Xizao, or Shower, is instructive in this regard. Set during the restructuring and rebuilding of Beijing in the 1990s, Shower tells the story of a family run bathhouse in a traditional urban community. It acts as a nexus between the public and private, as it "is not only a place to become clean, but also a social place where neighbors gather, exchange news, help and entertain each other" (200). Master Liu, the patriarch of the family who runs the bathhouse, represents the heart and history of this community; in addition to performing traditional Chinese acupuncture and bathing rituals he serves as a mediator for his clients' and neighbours' conflicts ranging from disputes over cricket fights to a couple's fraught marriage. While some critics have lauded the film for constructing a selforientalising fantasy, the power of this film comes precisely in its unwillingness to stage the life of its community, and thus traditional life as a whole, as a harmonious and yet diverse environment, where everyone has their place and all are de facto accepted into the fabric of social life. ${ }^{4}$ The point is that precisely because the private affairs of individuals extend out into the public spaces of the bathhouse and butongs, social order in Shower's traditional community is not a destructive force solely bent on "eliminating or reducing to a minimum the dark background of difference" as Arendt describes—rather, this extension allows for a minimal potential, but not guarantee, for heterogeneous identities to continuously be (re)negotiated and affirmed (Arendt: 33). However, when Master Liu dies at the end of the film, so too does the history and life of the community. As the last scene of the film 
depicts the once lively area reduced to rubble and a silent resignation of its inhabitants, Shower ultimately signals the irreversibility of economic development and the inability of the old world of China to survive the coming age of global modernity. It is with this conclusion in mind that we must return to the testimonies of $\mathrm{Mr}$. Han and Mrs. Zhang.

\section{The End of Histories and the Future of Economic Exile:}

From the time in which Mr. Han's family staged their protest in the early 2000s to Mrs. Zhang's resistance in 2013, the tenants of Chinese modernization drastically changed. This change can be represented by the ideological shift from President $\mathrm{Hu}$ Jintao's totalizing platform of "Harmonious Society" that was established in 2002, to current President Xi Jinping's universal proclamation of the "Chinese Dream" in 2013. In the first case, the insistence on harmony indicates the theoretical possibility for a plurality of voices to be tolerated within the transitional goals of economic reform; in the second, however, polyphony has been replaced by monophony, and in this sense the national demand for, and public interest in, modernity necessarily collapses into private identity.

Here, we must be willing to push this logic to its end if we are to understand the differing fates of Mr. Han and Mrs. Zhang's families. While Mr. Han's family was forcefully evicted in their nail-house protest, for the sake of "harmony" they were at least permitted to remain on the fringes of Chinese society, where they now represent "nothing but his own absolutely unique individuality" and are reduced to conditions of bare-life in the new Shanghai (Arendt: 33). For Mrs. Zhang and her family, however, their belief that "everybody has their own dream" completely misses the point that it is no longer a question of Chinese culture being replaced with the pursuit of profit, but that in the new Chinese Dream these two realities have become inseparable. Thus it is no longer the case that as Arendt maintained the public sphere is a space where "men cannot act or change at all"-even though they cannot act they must change to adopt the identity of modern citizens demanded by the global economic order or cease to exist.

It is precisely on this point that I would argue against Žižek's definition of global capitalism as it is articulated in The Parallax View. He writes that

capitalism is the first socioeconomic order which de-totalizes meaning: it is not global at the level of meaning (there is no global "capitalist-worldview," no "capitalist civilization" proper - the fundamental lesson of globalization is precisely that capitalism can accommodate itself to all civilizations, from Christian to Hindu and Buddhist); its global dimension can be formulated only at the level of truth-without-meaning, as the "Real" of the global market mechanism. (Žižek 2009: 181) 
The problem with this claim is that it fails to recognize how in capitalist modernity space has won over time, in a precise sense of producing local, individualized meaning that is nonexchangeable and yet somehow makes reference to the universal truth of the market mechanisms. In this way globalization forces the creation of local national worlds that are highly antagonistic to all others, including those within their own space. The truly global dimension of capitalism arrives in its ability to nullify not only rural provincialism, but urban diversity. And is there not a better image to demonstrate this than the negative spatiality of the nail-house, representing an inverted modern skyline where the space of private dwelling refuses to be levelled down to public, economic necessity? In 1955 Claude Levi-Strauss already warned against this phenomena in his Triste Tropiques, when he wrote that "mankind has opted for monoculture; it is in the process of creating a mass civilization, as beetroot is grown in the mass. Henceforth man's daily bill of fare will consist only of this one item" (Levi-Strauss 1992: 38). This one item, in the end, is the generation of profit and the exile from global civilization of those who refuse to comply.

In describing the refugee condition after the Second World War, Arendt firmly asserted the need to understand this phenomena as being within, not outside the prevue of Western civilization. In this regard, she writes that "the danger is that a global, universally interrelated civilization may produce barbarians from its own midst by forcing millions of people into conditions which, despite all appearances, are the conditions of savages" (Arendt: 34). Arendt's juxtaposition of civilization and savagery appears extreme and outdated. However, if we stop for a moment to consider the minimal difference between her statement and global capitalism's erasure of individual identity by leveling down particular cultures and history's to the goal of profit, the question of Arendt's new savagery becomes all the more poignant.

While nail-house protests complicate our traditional notions of the private and public sphere, it is no longer enough to see in the erasure of traditional communities an example of the return of the repressed; something does returns to us, the Western observer, but it is greater than our own history. What returns to us in an analysis of these two new phenomena is the perpetuation of a logic of domination that while locally taking root in the $19^{\text {th }}$ century has now completely overrun the globe. And so the subtle shift in the language of globalization from a first, second and third world to that of developed, developing and under-developed economy signals a meager movement from political economy to economics as such. China, then, is not an exception or even alternative to the rule of global modernity but the logical conclusion of a system that no longer believes the principle that, to invoke Edmund Burke, wealth has its limits. And in this precise sense, perhaps contemporary China and its recent history no longer reveals to us only the worst elements of our past, but presents us with a startling image of our future: a space overwhelmed by urban excess that is defined by its ability to produce homogeneous subjects bearing the mark of universal economic exile. 


\section{Notes}

1. For a comparative discussion of Western and Chinese urbanization and infrastructural growth see Timothy B. Weston, "China's Historic Urbanization: Explosive and Challenging" in China in and Beyond the Headlines, ed. Timothy B. Weston and Lionel M.Jenson.

2. See Roger des Forges and Luo Xu "China as a Non-Hegemonic Superpower? The Uses of History by the 'China Can say No Writers' and their Critics" in Critical Asian Studies Vol. 33 No. 4 (December, 2006) 463-485 and see Chapter 5 "Alternatives? The PRC and the Global South" in Arif Dirlik, Global Modernity: Modernity in the Age of Global Capitalism. (London: Paradigm Publishers, 2007).

3. The term "men" is that used by Arendt. This term shall reappear as well in the work of Claude Levi-Strauss later on in this paper. I have opted to retain the original vocabulary of the author; while this term is not neutral, its usage here reflects its historical inflection to stand in for humanity writ-large. While, again, a problematic turn it is my view that to edit it out would be a disservice not only to Arendt's work but moreover the present age as it ends up flattening discourse to a single, ahistorical cosmology that does not confront but elides the past.

4. With regards to this critique of Shower as self-orientalising, Jing Nie writes that film seems to appeal to "the globalized western countries [who] eagerly seek heterogeneity and diversity to counterbalance their keenly felt homogenization" (202).

\section{References}

Arendt, Hannah. 1949. “The Rights of Man, What are They?” Modern Review 3(1): 24-37.

des Forges, Roger and Luo Xu. 2006. "China as a Non-Hegemonic Superpower? The Uses of History by the 'China Can say No Writers' and their Critics." Critical Asian Studies 33 (4): 463-485.

Dirlik, Arif. 2007. Global Modernity: Modernity in the Age of Global Capitalism. London: Paradigm Publishers.

Jameson, Frederic. 1998. "Notes on Globalization as a Philosophical Issue." In The Cultures of Globalization, edited by Fredric Jameson and Masao Miyoshi. Durham and London: Duke University Press.

Jing Nie. 2009. "A City of Disappearance: Trauma, Displacement, and Spe tral Cityscape in Contemporary Chinese Cinema." In Chinese Ecocinema: In the Age of Environmental Challenge, edited by Sheldon H. Lu and Jiayan Mi. Hong Kong: Hongkong University Press.

Levi-Strauss, Claude. 1992. Tristes Tropiques. New York: Penguin Books.

Lin Binyan. 1990. China's Crisis, China's Hope: Essays from an Intellectual in Exile.

Cambridge, Massachusetts: Harvard University Press.

Shepard, Wade. 2015. Ghost Cities of China: The Story of Cities without People in the World's Most Populated Country. London: Zed Books. 
Su Xiaokang and Wang Luxiang. 1994. Deathsong of the River: A Reader's Guide to the Chinese TV Series Heshang, translated by Richard W. Bodman and Pin P. Wan. Ithica, New York: Cornell University Press.

Weston, Timothy B. 2008. China's Historic Urbanization: Explosive and Challenging. In China in and Beyond the Headlines, edited by Timothy B. Weston and Lionel M. Jenson. New York: Rowman and Littlefield.

Zhang Yiwu. 2011. “Žižek's China, China's Žižek.” positions. 19(3):723-737

Žižek, Slavoj. 2009. The Parallax View. Cambridge, Massachusetts: The MIT Press. 